\title{
A Study of Market Scale and Share Estimation Methodology on Effective Feasibility Analysis of IT R\&D Program Using Fuzzy \& Big Data
}

\author{
Jae Hyuk Cho \\ Korea Institute of S\&T Evaluation and Planning \\ cool@kistep.re.kr
}

\begin{abstract}
Standardizing the various benefits and performance features of the different government $R \& D$ programs is difficult. This is largely because each of them involves a wide variety of necessary research. In order to minimize benefit distinctions--the difference in benefit between the proposal and the alternative--the OECD benefit assessment report was examined. Associated Research results and benefit distinctions from preliminary feasibility data were also used to draw benefit estimation hindrance factors. Analytic Hierarchy Process is used to identify the relative importance rank of benefit estimation hindrance factors. If Independence between benefit estimation hindrance factors fails to satisfy the evaluation criteria then, a model based on the fuzzy measure is applied. This is for drawing optimal evaluation results, In order to know the correlation between benefit distinctions and benefit estimation hindrance factors ordered digit model is utilized. The application of big data technique is used as a means to collect extensive trend data and adequately capture technology trends. In this paper, the $R \& D$ program related to Information Technology was classified into four categories (Firstmover, Catch-up, Data existence). Finally a methodology for extracting a relevant market scale and a market share data is proposed.
\end{abstract}

Keywords: Fuzzy Measure; Big Data; Analytic Hierarchy Process; Feasibility Analysis; Market Scale and Share Estimation

\section{Background}

In the IT industry, there exists a difficulty in estimating the benefit of promoting $R \& D$ programs that consist of convergence researches (i.e., technology development and foundation establishment) or has field-specific characteristics. Especially, drawing correlation and causation between the R\&D input and these output, estimating different sources of benefits and identifying all beneficiaries of research outputs are difficult. Standardizing the various benefits and performance features of the different government $\mathrm{R} \& \mathrm{D}$ programs is difficult.

This is largely because each of them involves a wide variety of necessary research. Therefore, benefit estimation hindrance factors are deducted by analyzing the OECD benefit assessment report. Associated preceding research results and related preliminary feasibility data were also used. The deducted benefit estimation hindrance factors can be considered as an important indicator ensuring consistency and objectivity during project feasibility analysis. The evaluation receivers' work effectiveness will be enhanced by providing objective basis for detecting the under or over-estimated benefits factors and adjusting these benefit gaps more accurately based on a valid evidence. 


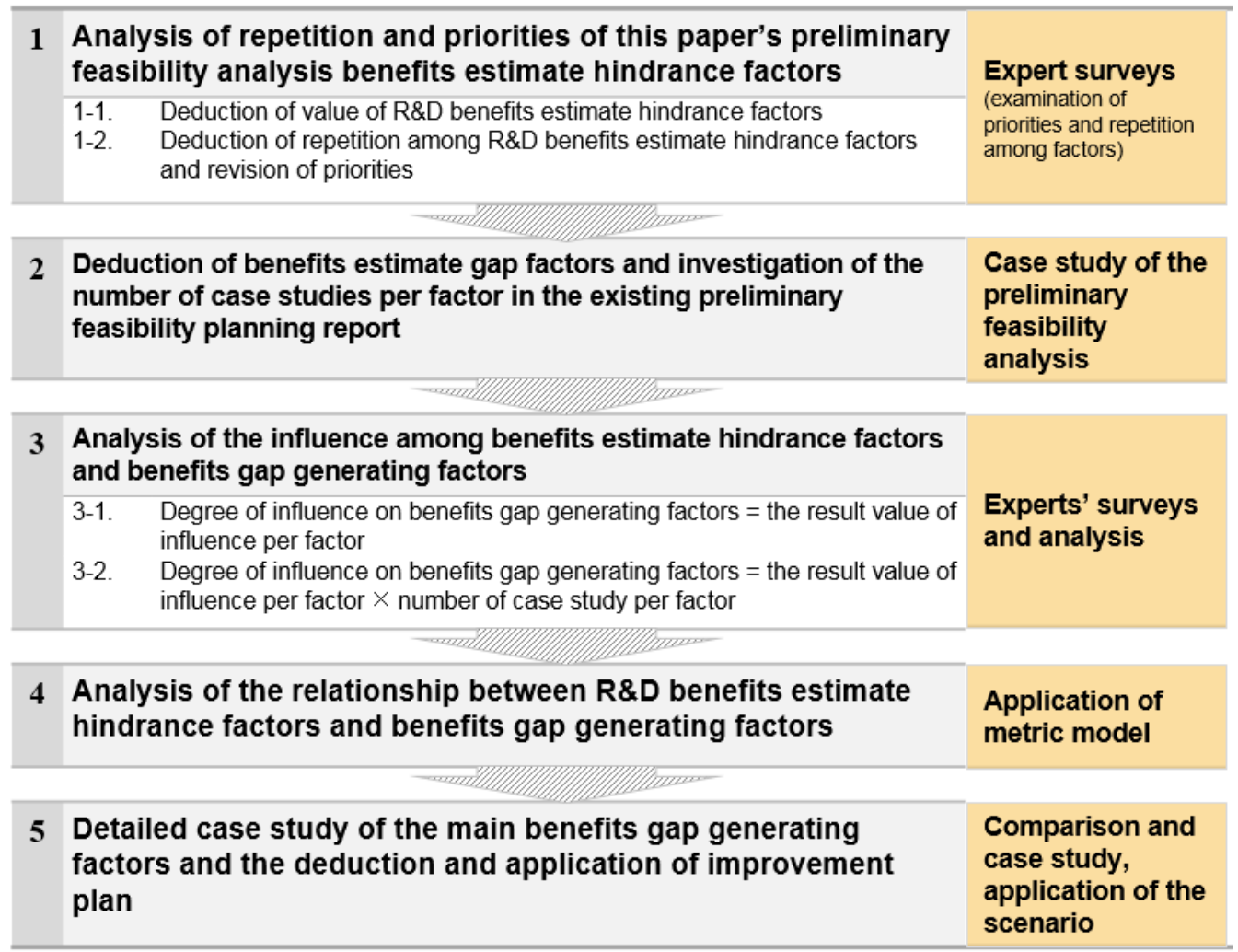

\section{Figure 1. Conceptual Scheme of the Research}

Research team's reviews on the method of estimating benefit we analyzed the estimate benefit gap and presented a corresponding plan. Also, we proposed a practical standard and a guideline that can minimize the benefit gap. Analytic Hierarchy Process(AHP) is used to identify the relative importance rank of benefit estimation hindrance factors. If Independence between benefit estimation hindrance factors fails to satisfy the evaluation criteria then, a model based on the fuzzy measure is applied. This is for drawing optimal evaluation results, In order to know the correlation between benefit distinctions and benefit estimation hindrance factors ordered digit model is utilized. The application of big data technique is used as a means to adequately capture a relevant market scale and a market share data - the key factors of causing benefit distinctions. On the basis of this, the improvement plan of $\mathrm{R} \& \mathrm{D}$ benefits estimation was deducted.

\section{Preceding Researches and Factors Causing Benefit Distinctions}

\subsection{OECD Case Analysis}

According to the OECD report, there are nine key challenges for evaluating the R\&D program benefit estimation (shown in Table1.). 


\section{Table 1. The Main Challenges for Evaluating R\&D Program Benefit}

\section{Estimation}

\begin{tabular}{|l|l|}
\hline Criteria & Main Challenges \\
\hline \multirow{3}{*}{ Product } & 1. Causality and Sector Specificity \\
\cline { 2 - 2 } & 2. Multiple Benefits \\
\hline \multirow{3}{*}{ Process } & 3. Identification of Users \\
\cline { 2 - 2 } & 4. Interdisciplinary Outputs \\
\hline \multirow{3}{*}{ Valuation } & 6. Complex Transfer Mechanisms \\
\hline & 7. Time Lags \\
\hline & 9. Monetary Valuation \\
\hline
\end{tabular}

Resource: OECD DSTI (Directorate for Science, Technology and Industry)

The OECD analysis quotes "Each country is putting in effort to develop a more efficient new analysis method by quantitative analysis, data-based approach and case studies when estimating product of the public R\&D investment and social benefit." However, it is presented that benefits analysis of $R \& D$ businesses generate numerous benefits target various ripple effects, and is difficult to make an accurate assessment of the benefits numerical value. From these research results we can see that assessing the benefits numerical value and adjusting the benefits estimated value is a very difficult process.

\subsection{Existing Researches}

Research on the analysis of 4 items, pregnancy period, benefits period, R\&D contribution rate, programs contribution rate, was done [2]. Recent preliminary feasibility analysis shows that there are numerous businesses with various industries fused together or with both original technology research and commercialization. Therefore, they claim that applying the same pregnancy period and benefits period uniformly to each program is not appropriate. Analysis of existing research related to feasibility verification, of cost benefits analysis was done synthetically in order to organize benefit assessment and measurement related main pending problems [3]. These pending problems can be categorized into errors in the cost benefits analysis principle application, rash optimism in the regulation effect, simple errors, etc. In the case of (A), like regulations of the building industry, it was proposed that when the benefits period lasts a long time, as in 50 years, a discount on the benefits is necessary. However, IT program's benefits period lasts a short time of approximately 10 years, thus, this paper does not consider the corresponding pending problem. 


\section{Table 2. Categories of Errors in the Existing Benefits Estimation} Researches

\begin{tabular}{|c|c|}
\hline Criteria & Content \\
\hline \multirow{4}{*}{$\begin{array}{l}\text { Errors in applying standards } \\
\text { of cost benefits analysis }\end{array}$} & Decrease or exclusion of discount of long-term benefits(A) \\
\hline & Problem of calculating repetition of benefits(B) \\
\hline & General appropriation of indirect benefits $(\mathrm{C})$ \\
\hline & Exclusion of distributive priorities(D) \\
\hline \multirow[t]{2}{*}{$\begin{array}{l}\text { Rash optimism on about } \\
\text { regulation effect }\end{array}$} & $\begin{array}{l}\text { Determination of goal achievement rates and compliance rate deficient of } \\
\text { realistic validity(E) }\end{array}$ \\
\hline & Rash optimism or exaggeration of regulation effect $(\mathrm{F})$ \\
\hline Simple error & $\begin{array}{l}\text { Simple error originating from assumptions or prospects made without } \\
\text { evidence or basis }(G)\end{array}$ \\
\hline
\end{tabular}

In each case of 87 subject projects for the benefits estimation, the concept of distributive priorities was not reflected.

\subsection{The Case of Preliminary Feasibility Analysis}

In this paper, we examined all of the rearranged potential benefits cases in the preliminary feasibility planning reports from the 33 R\&D programs from 2011 to 2013 confirmed by the government agency. We identified and accessed the rearranged benefit factors in the corresponding preliminary feasibility analysis - that can be categorized in twelve items.

Table 3. The Main Factors Casing Benefit Distinctions

\begin{tabular}{|c|c|}
\hline & Items \\
\hline $\begin{array}{ll}\text { Twelve } & \text { factors } \\
\text { casing } & \text { benefit } \\
\text { distinctions } & \end{array}$ & $\begin{array}{l}\text { Success rate of R\&D commercialization, business } \\
\text { contribution rate, benefits period, ratio of value added, } \\
\text { R\&D contribution rate, market size, market share rate, } \\
\text { indirect benefits, repetition among benefits factors, } \\
\text { pregnancy period, benefits from transfer and rate of social } \\
\text { discount }\end{array}$ \\
\hline
\end{tabular}

\subsection{AHP and Utilization of Fuzzy Measurement}

Analytic Hierarchy Process (AHP) is the process of making a pairwise comparison matrix - it is a task of setting a priority comparing each factors in relation to the element of the next higher level for a specific decision and then it shows factors in a hierarchic structure. From this matrix, a normalized priority vector affiliation importance rate on each level of the layer is calculated by utilizing the Eigen Value Method [2].

Fuzzy Measures, as an extended concept of probability measurement, is known as a highly effective measurement utilized especially in evaluation problem's that are not additive, and are non-additive. The non-additivity in fuzzy measures indicates that when evaluation value of item $A$ is 0.2 and item $B$ is 0.5 , the evaluation value considering both $\mathrm{A}$ and $\mathrm{B}$ may not be 0.7 . When the evaluation value of both $\mathrm{A}$ and $\mathrm{B}$ is bigger than 0.7 the two items have a synergy effect, while the opposite indicates that the two have a cancellation effect. Correspondingly, in most decision making processes there exists a correlation among the evaluation standard, making it non-additive. Thus, fuzzy measures is known as a measurement that can reflect the problem better compared to the general addition measurement in the decision making process. 


\subsection{Utilizing Big Data Technique}

Considering the information-oriented society in which recent information is being digitized and real time data in large scale are appearing in various fields of study, there appears to be limitations in analyzing the technology and market flow with only limited information from patents and papers. Acquisition of information has become prompt and precise compared to the past by means of the development of analytical technique, and collection of data utilizing big data in the web environment. The Korea Institute of Science and Technology Information (KISTI) conducted research to develop a big data analysis service model and verify its validity. This was through analysis of job creation and of technology life cycle that could be utilized as basis information of market size or market share rate, focusing not only on government R\&D information but also on SNS and social media. The Department of Energy (DOE) reduced the installation cost of the relevant equipment when solar energy R\&D 'Sunshot Initiative' by utilizing not only patents but also news articles to analyze the market of solar energy generation.

\section{Benefits Estimation Hindrance Factor Analysis Methods}

\subsection{Deduction of Benefits Estimation Hindrance Factors}

The nine key challenges for evaluating the $R \& D$ program benefit estimation suggested by the OECD that are relevant to the twelve factors casing benefit distinctions deducted from the preliminary feasibility analysis case study and to the seven main pending issues related to existing research's assessment and measurement of benefits. The nine factors OECD presented that make it difficult to estimate benefits are analyzed to be relevant to the twelve benefits estimation generating factors deducted from the preliminary feasibility analysis case analysis and to the seven main pending issues related to existing research's assessment and measurement of benefits. The nine OECD factors mentioned above are relevant to the factors of the existing research excluding 'the exclusion or reduction of discounts of the long term benefits', 'Exclusion of distribution type's weight', and 'Exaggeration of restriction effectiveness or excessive optimism'. The following Table 4, shows benefit estimation hindrance factors and these factors can be utilized as the main considerations which can enhance the objectivity and consistency of benefit estimation process during a feasibility analysis. The interrelationship between the benefits estimation hindrance factors, the OECD, the existing research and case study are as shown in the table below. 
Table 4. Benefit Estimation Hindrance Factors

\begin{tabular}{|c|c|c|}
\hline criteria & $\begin{array}{l}\text { benefits estimate hindrance } \\
\text { factors }\end{array}$ & contents \\
\hline \multirow{5}{*}{$\begin{array}{l}\text { PRODUCT } \\
\text { (A) }\end{array}$} & $\begin{array}{l}\text { Unclarity of the cause-and effect } \\
\text { relationship between investment } \\
\text { according to business characteristic } \\
\text { and the product(1) }\end{array}$ & $\begin{array}{l}\text { Problem due to the absence of the direct link between } \\
\text { the research investment and product }\end{array}$ \\
\hline & $\begin{array}{l}\text { Generation of various and broad } \\
\text { benefits(2) }\end{array}$ & $\begin{array}{l}\text { Problem due to the difficulty in estimating product } \\
\text { though creation of various product in possible in the } \\
\text { basic research }\end{array}$ \\
\hline & Difficulty in estimating product(3) & $\begin{array}{l}\text { Problem is due to the difficulty of identifying all of } \\
\text { the beneficiaries of the research product and the } \\
\text { additional cost in doing this }\end{array}$ \\
\hline & $\begin{array}{l}\text { Difficulty in measuring the extemal } \\
\text { influence individual from the } \\
\text { research investment(4) }\end{array}$ & $\begin{array}{l}\text { Difficulty in measuring all of the social benefits in } \\
\text { order to assess social contribution of a particular } \\
\text { research product }\end{array}$ \\
\hline & $\begin{array}{l}\text { Difficulty in assessing the benefits } \\
\text { caused by the environment variable } \\
\text { such as policies, regulations and } \\
\text { legal systems(5) }\end{array}$ & $\begin{array}{l}\text { Though the research can proceed through new } \\
\text { policies, regulations and legal systems, due to the } \\
\text { uncertainty of future regulation enforcement and } \\
\text { regulation observance rate it is difficult to estimate } \\
\text { the benefits. }\end{array}$ \\
\hline $\begin{array}{l}\text { PROCESS } \\
\text { (B) }\end{array}$ & $\begin{array}{l}\text { Complexity in the research product } \\
\text { and product transfer methods }(6)\end{array}$ & $\begin{array}{l}\text { There is difficulty in understanding and } \\
\text { distinguishing the whole structure in which the } \\
\text { research product is delivered into society. }\end{array}$ \\
\hline
\end{tabular}

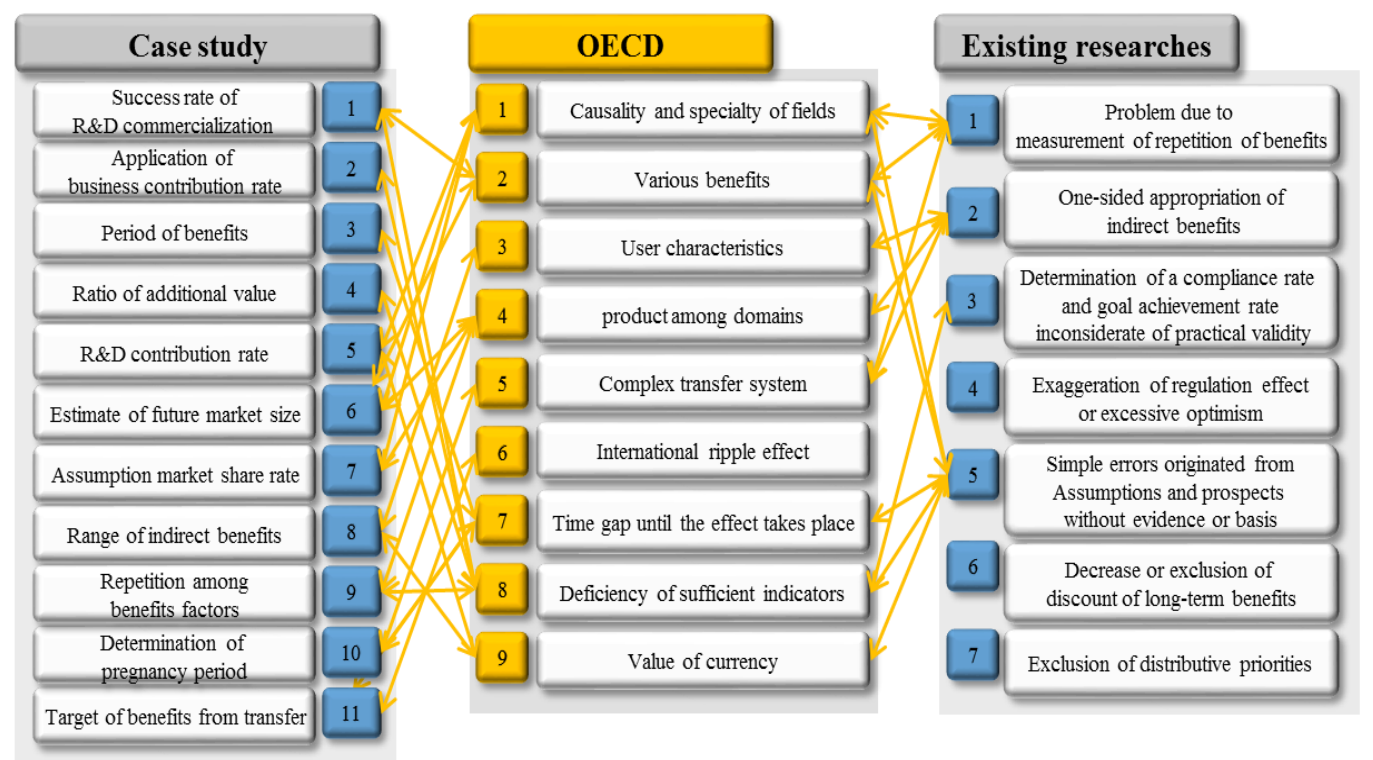

Figure 2. The Interrelationship between the OECD, the Existing Researches, and Case Study

\subsection{Deduction of the Degree of Importance and Repetition of Benefits Estimation Hindrance Factors}

The degree of importance (priority) of benefits estimation hindrance factors was deducted utilizing the AHP method. The AHP works on the assumption that the assessment standards are independent of each other. Therefore it cannot take into consideration the interaction effect of general assessments in which assessment standards are dependent of each other. The method of granting importance by AHP analyzes on the assumption that assessment standards are independent of one another. Therefore the inability to take into consideration the interrelationship between the standards are a limitation. However, in real-life decision making, many standards are mostly 
interconnected than independent because of a diversity of reasons such as the assessor's personal opinion or ambiguous standards.

According to fuzzy measure theory [5] it is possible to measure the connection between assessment standards, and by utilizing this the optimum degree of importance among benefits estimation hindrance factors considering the repetition among hindrance factors were deducted. We assume the degree of repetition among hindrance factors does not exceed $50 \%$ because when a survey is done simply by pair wise comparison, the degree of repetition tends to be overestimated because of the linguistic vagueness. The deducted degree of repetition is applied to the priorities per item.

[Step 1] Apply the priority $(\omega)$ of the benefits estimation hindrance factors found by utilizing AHP and deduct the repetition coefficient $(\lambda)$ among hindrance factors through surveys to experts.

[Step 2] Find the fuzzy measure $\mathrm{g}(\cdot)$ by utilizing the priority $(\omega)$ and the degree of repetition among hindrance factors. When doing this, use the same shape definition function proposed by Tsukamoto to calculate the $g(\cdot)$. Equation (1) is Tsukamoto, $\lambda$ fuzzy measure.

$$
\begin{gathered}
f \lambda(\omega)=\left((1+\lambda)^{w}-1\right) / \lambda \text { if } \lambda \neq 0 \\
=\omega \\
\text { if } \lambda=0
\end{gathered}
$$

Here, $(\omega)$ is the same as the fuzzy measure $g(\cdot)$ function and $\omega$ is the same as the degree of importance $(\omega)$ found from the priorities of the benefits estimation hindrance factors.

[Step 3] Find the fuzzy measure with the degree of repetition applied and compare it with the deducted degree of importance $(\omega)$ per hindrance factor.

When you calculate the degree of repetition for each class, the figures will be classified into 3groups: the product's formation process, the product's delivery process, and the aspect of evaluation. The repetition figures will be considered inside each group. In the product formation process, the ambiguity of the cause-and-effect relationship among product and the investment according to program characteristic overlap a lot with the other items.

Table 5. The Fuzzy Measure Figures G(• ) and its Ranking

\begin{tabular}{|c|c|c|}
\hline Level 2 & Level 3 & Rank \\
\hline \multirow{3}{*}{$\begin{array}{c}\text { Product } \\
\text { (A) }\end{array}$} & $(1)$ & 0.1222 \\
\cline { 2 - 3 } & $(2)$ & 0.0895 \\
\cline { 2 - 3 } & $(3)$ & 0.0706 \\
\hline \multirow{2}{*}{ Process } & $(5)$ & 0.0776 \\
(B) & $(6)$ & 0.0617 \\
\cline { 2 - 3 } & $(7)$ & 0.0742 \\
\hline Valuation & $(8)$ & 0.0678 \\
(C) & $(9)$ & 0.2281 \\
\hline
\end{tabular}

This is the fuzzy measure figure we calculated out of the degree of importance $(\omega)$ of hindrance factors and the repetition coefficient $(\lambda)$. Through comparison, we can see that the degree of importance $(\omega)$ found by utilizing the AHP method and the fuzzy measure figure $\mathrm{g}(\cdot)$ found by applying the repetition coefficient have changed. 
Table 6. The Difference between the Priorities and the Fuzzy Measure Figure

\begin{tabular}{|c|c|c|c|c|}
\hline Rank & Level 2 & Level 3 & Importance & Fuzzy measure figure \\
\hline \hline 1 & (C) & $(8)$ & 0.2046 & 0.1869 \\
\hline 2 & (B) & $(6)$ & 0.1552 & 0.1503 \\
\hline 3 & (A) & $(1)$ & 0.1552 & 0.1470 \\
\hline 4 & (C) & $(9)$ & 0.1310 & 0.1182 \\
\hline 5 & (B) & $(7)$ & 0.1071 & 0.1145 \\
\hline 6 & (B) & $(5)$ & 0.0920 & 0.0896 \\
\hline 7 & (A) & $(7)$ & 0.0741 & 0.0713 \\
\hline 8 & (A) & $(3)$ & 0.0437 & 0.0423 \\
\hline 9 & (A) & $(2)$ & 0.0776 & 0.0364 \\
\hline
\end{tabular}

When considering the interaction between attributes when analyzing the benefits estimation hindrance factor, we could see from comparison the degree of importance of difficulty in choosing the adequate benefits attribute indicator, the effect of relocation and relocation benefits, the ambiguity of the cause-and-effect relationship between products and investment according to program characteristic, the complexity of research products and the result transferring methods, diverse and wide range benefits generation, etc decreased, the importance of difficulty of benefits estimation occurring with a time difference increased.

\subsection{Analysis of the Relationship between Benefits Estimation Hindrance Factors and Benefits Gap Generating Factors}

Commonly the connection between benefits estimation hindrance factors and the preliminary feasibility benefits gap generating factors can be made through the qualitative method. However, there is difficulty in determining through the quantitative method by this connection. Therefore in this case, the preliminary feasibility analysis benefits gap generating factors' degree of importance are found by analyzing these connections because through these connections the benefits gap generating factors' priorities can be deducted. However in order to assume this model the cause-and-effect relationship needs to be theoretically valid. Because the mathematical methodology was not yet established and due to the difficulty in confirming the clear cause-and-effect relationship, we intend to analyze the relationship through the collection of sufficient data. Because the benefits estimation hindrance factors and preliminary feasibility analysis benefits gap generating factors' variables have a ranking of priority, they can be calculated by utilizing the Ordered Logit model, which is the representative of metric models considering the order of priority.

$$
\begin{aligned}
& P_{\Gamma}\left(y_{j}=i\right)=P_{\Gamma}\left(K_{i-1}<\beta_{1} x_{1 j}+\beta_{2} x_{2 j}+\ldots \ldots \beta_{k j} x_{k j}+\mu_{j} \leq k_{i}\right) \\
= & \frac{1}{1+\exp \left(-k_{i}+X_{i \beta}\right)}-\frac{1}{1+\exp \left(-k_{i-1}+X_{j} \beta\right)}
\end{aligned}
$$

$\left(\mathrm{y}_{\mathrm{i}}\right)$ refers to the priorities of the benefits estimation hindrance factors. However, when the AHP method is applied, it may affect the degree of repetition among hindrance factors. Therefore the variable needs to be divided in to 2 cases: the one with the repetition degree applied and one without. $\left(\mathrm{x}_{\mathrm{i}}\right)$ refers to the preliminary feasibility analysis benefits gap generating factors' priorities deducted from experts' surveys through the preliminary feasibility analysis case studies. STATA, a useful program in estimating the Ordered Logit model, was utilized as the statistics program to assume this model.

First let's examine the case in which the degree of importance of benefits gap 
generating factors are not applied. This model consists of the cause-and-effect relationship but when the relationship is not obvious it can be interpreted into the problem of how much they are associated about the relative degree of importance. Thus, by comparing the independent variable coefficient, we can analyze the degree of importance of the benefits gap generating factors.

The results deducted from the Ordered Logit model without the degree of repetition applied is as follows. As a consequence of the test significant level verification at the level of $90 \%, 95 \%$, and $99 \%$, the transfer benefits, the repetition among benefits items and pregnancy period are meaningless for they did not included the significant level in each, reliability test, and so the degree of importance was only shown for the 8 items that arrived at the significant level and is as shown below.

\begin{tabular}{|c|c|c|c|c|c|c|}
\hline \multicolumn{2}{|c|}{ Benefits gap generating factors } & \multicolumn{3}{|c|}{ Benefits gap generating factors } & \multicolumn{2}{|c|}{ Benefits gap generating factors } \\
\hline \multicolumn{2}{|c|}{$\begin{array}{l}\text { Un-reflected priorities of } \\
\text { benefits estimation hindrance } \\
\text { factors }\end{array}$} & \multicolumn{3}{|c|}{$\begin{array}{l}\text { Reflected priorities of benefits } \\
\text { estimation hindrance factors }\end{array}$} & \multicolumn{2}{|c|}{$\begin{array}{l}\text { Excluded R\&D contribution } \\
\text { rate and reflected priorities of } \\
\text { the benefits estimation } \\
\text { hindrance factors. }\end{array}$} \\
\hline \multirow[t]{2}{*}{$\begin{array}{l}\text { Reviewed overlapping } \\
\text { factors among benefits } \\
\text { gap generating factors }\end{array}$} & \multicolumn{2}{|c|}{$\begin{array}{l}\text { Excluded } R \text { \& } D \\
\text { contribution rate due to a } \\
\text { simple error in the figures } \\
\text { Changes }\end{array}$} & \multicolumn{2}{|c|}{$\begin{array}{l}\text { Benefit period } \\
\text { excluded-due to } \\
\text { long duration in IT } \\
\text { sectors }\end{array}$} & \multicolumn{2}{|c|}{$\begin{array}{l}\text { Transfer benefits included - } \\
\text { due to importance and } \\
\text { insufficient meanings of } \\
\text { existing definition }\end{array}$} \\
\hline & $(0.5514)$ & $\mathrm{R} \& \mathrm{D}$ contributior & & $(0.9754)$ & market size & $(0.7894)$ \\
\hline indirect benefits & $(0.3108)$ & market share rat & & $(0.9220)$ & market share rate & $(0.5200)$ \\
\hline $\begin{array}{l}\text { Success rate of R\&D } \\
\text { commercialization }\end{array}$ & $(0.2961)$ & indirect benefits & & $(0.7473)$ & project contribution rate & $(0.3692)$ \\
\hline ratio of value added & $(0.2952)$ & benefits period & & $(0.5918)$ & benefits period & $(0.3271)$ \\
\hline market size & $(0.1783)$ & project contributi & & $(0.4558)$ & indirect benefits & $(0.2101)$ \\
\hline R\&D contribution rate & $(0.0426)$ & ratio of value ad & & $(0.4447)$ & $\begin{array}{l}\text { Success rate of R\&D } \\
\text { commercialization }\end{array}$ & $(0.1501)$ \\
\hline market share rate & $(0.0386)$ & market size & & $(0.4266)$ & ratio of value added & $(0.0738)$ \\
\hline project contribution rate & $(0.0157)$ & $\begin{array}{l}\text { Success rate of } \\
\text { commercializatio }\end{array}$ & & $(0.1965)$ & - & \\
\hline
\end{tabular}

\section{Figure 3. Fuzzy Measurement and AHP used to get Benefit Gap Generating Factors}

The importance of the R\&D contribution rate, market share rate and indirect benefits was presumed in order by utilizing the data with the repetition degree applied to the dependent variable. Because the $R \& D$ contribution rate is classified as a simple error, the independent variable needs to be presumed without it. From this the degree of importance of market size, market share rate and project contribution rate appear in order.

\section{Assessment of Market Size, Market Share Rate or the IT Department}

\subsection{Assessment Methods of Market Size, Market Share Rate}

Previously, the direction of improvement and case application was performed focusing on market size, market share rate in order of importance. The rate of market growth was proposed mostly by utilizing the experts' surveys in the planning report and was applied to the preliminary feasibility analysis without much modification. The standard of the target market and a quantitative analysis method for the rate of market growth provided in the planning report is not clearly presented in the preliminary feasibility analysis and therefore a direct of approach about this and a direction of improvement for the quantitative analysis needs to be suggested.

By analyzing the existing examples of calculating the market share rate we can see that the planning report utilized the Delphi technique and conjoint analysis and the 
preliminary feasibility report applied the market share rate assessment method as it is except in some scenarios according to the possibility of achieving the market share rate.

The 2 main factors in estimating market size is setting the standard for market scale and setting the rate of market growth. When assessing the market scale by dividing it, reliability of splitting market needs to be secured by comparing the total of the splitted parts and the whole scale of the market related to the research. This is because when splitting the market, market size assessment criteria from the data source generates repetition problems. In order to apply the splitted standard, a reliable set of data source needs to be provided by comparing and analyzing the splitted market with the whole, and utilizing big data technique.

Considering the fact that almost none of IT research and development programs are put to an end in the original technology stage, most businesses have a high probability of proceeding with the goal of TRL 7 8 out of the 8 types shown in the Figure 4 below. Therefore this paper intends to propose a direction of improvement focused on the 2 types $\mathrm{C} 3$ and F3 as shown below when analyzing market size, market share rate of IT research and development programs.

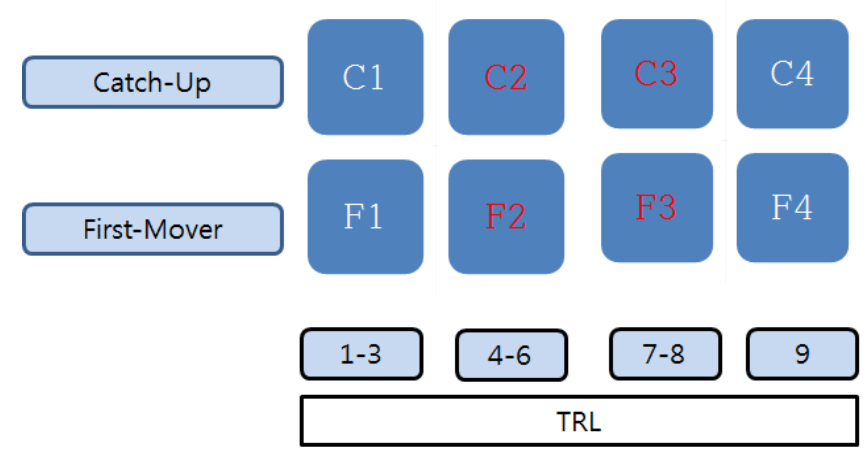

Figure 4. The Types of Experimental Subject Analysis for Market Size and Market Share Rate

This paper limits the rage of analysis to the research and development programs in the IT department and divides it into 4 types and provided a direction of improvement for each, which is considered to be the research's new approach and result. The 4 types are first classified into Catch-Up and First-Mover according to the level of technology, and then is divided by whether the corresponding market size data exists or not in order to provide an improvement plan to assess the market size. The classification of Catch-Up and First-Mover programs are whether the internal corresponding IT research and development technology is included in the leading technique market, and the fact of existence and nonexistence depends on whether there are enough data to utilize the metric model or not. In the case of a Catch-Up program with data, they utilize the spreading model like Gomperz. In the case of First-Mover programs, the relationship between similar market share rate and the main cause that effects it is assumed and the time series model like ARIMA is assumed on the basis of it, finally estimating the market share rate. The ARIMA model is a kind of time series model that utilizes auto regression, integral calculus and moving average synthetically to assume. In the case of Catch-Up programs without data, they utilize experts' surveys in short-term forecasts and CAGR in mediumand long-term forecasts to assume the market size. In this case reliability can only be provided when the corresponding market is in stabilizer. In the case of First-Mover programs assuming market size by conjoint analysis through experts' surveys is recommended.

Unlike market size, assuming market share rate is affected by various factors and so it is important to examine the direction of prediction of market share rate before analyzing it 
quantitatively. It is also important to understand how much the research and development program affects the expansion of market share rate. This paper utilizes the metric model to analyze the relationship between patent index (CPP, PII, etc.) and market share rate of similar market in order to understand the direction prediction of market share rate and the degree of impact the $R \& D$ has on market share rate. There are a variety of indicators that represent the technology of research and development such as patent index, technique level, commercialization result(amount), royalty, etc. However the problem of multicollinearity can arise and therefore the most reliable indicators among them, which is the patent index, is used. If the coefficient of patent index is $(+)$, the R\&D program has a positive influence on the expansion of market share rate. How big the coefficient is can provide a basis for how much the $R \& D$ technique affects the expansion of market share rate

In the case of Catch-Up programs with data, market share rate can be assumed by utilizing linear model or sale response model that can assume changes in the market share rate by marketing factors.

[1] Determine the leading market of the divided market

[2] Secure past market share rate data of the leading market (The utilization of reliable data source is needed. Reverification considering the whole market share rate

[3] Consider the adjustment and direct independent variable, secure time series data

[4] Utilize the Panel model, Analyze the degree of impact of the adjustment and direct independent variable on market share rate

[5] Utilize the time series data of each independent variable. Assume the future estimate of independent variable

In the case of First-Mover programs, market share rate can be assumed by utilizing the Differential Game Theory model which can analyze the change in market share rate according to marketing factor's application or not after the end goods of R\&D has been applied.

[1] Apply the Hamiltonian function of the Differential Game Theory

[2] Secure the past sales data of similar market, secure the market share rate data of the domestic and abroad, secure time series data

[3] Utilize a software that is smooth with programing such as R or MATLAP to set the model

[4] Utilize the time series of the similar market sales to assume the estimate in AR model and assume the market share rate by utilizing the relationship between market share rate and sales

Catch-Up programs without data rely on experts' surveys but that alone may be difficult to provide an objective basis to assume the future market share rate. Therefore discrete response model needs to be considered as well to assume market share rate. discrete response model is a methodology that secures the market share rate data by experts' surveys and understands and applies these influences to the independent variable.

[1] Application of Delphi technique by experts' surveys.

[2] Utilize the DRM(Discrete Response Model). (dependent variable: market share rate provided in the surveys, independent variable: factors that affect market share rate)

[3] When the coefficient of independent variable is assumed deduct the future value utilizing the time series model

[4] Assume market share rate by applying the future value of the independent variable to the discrete response model

In the case of First-Mover programs the market share rate is determined primarily by conjoint analysis by experts' surveys and on the basis of this market share rate can be assumed by applying the bootstrapping or the Agent Based Modeling. Agent Based Modeling makes it possible to understand the amount of influence $R \& D$ program has on market share rate by assuming the exceptional part of market share rate forecasting of $\mathrm{R} \& \mathrm{D}$ program: the changes in market share rate due to marketing factors. Agent Based 
Modeling is a method that assumes the market share rate by simulation of the changes in incentives that are given to the final beneficiary of the R\&D program. Examples of these incentives can be supported technique given to small program or promotion of small hidden champion in the R\&D program.

\subsection{Utilization of Big Data}

The securement of high quality data needs to be precedent for the most efficient analysis of the preliminary feasibility analysis utilizing big data. Besides the papers and patents, the data possessed by the government or public organization are much more reliable and large scale data compared to those in the web. Data in the web can also be utilized as high quality data like papers and patents when there is a way to provide reliability and influence. Collection of data is needed not only from patents and papers but also from the web in order to grasp the stream of market and high technology of the targeted programs of preliminary feasibility analysis. In the existing research [6], web data can be collected through development of the Web Crawler which is on the basis of the Google search engine (Web Search API). The proposed Web Crawler [6] in particular was developed to collect data from high credibility web sites such as government and public web sites for a specific period.

In this paper the Web Crawler can be utilized to understand the amount of influence the core technology of the targeted programs of preliminary feasibility analysis has relatively in the corresponding field of technology. The wearable technique program among those targeted by preliminary feasibility analysis can be shown as an example. The technical influence among the core technology (material, component, platform, input, output, processing, and power) and its upper level (wearable and device) is comparatively analyzed to understand the influence of the core technology of the preliminary feasibility analysis. To accomplish this 2 types of data search key words are deducted as shown, and each keyword is applied to the Web Crawler targeted on government and public web sites to collect relevant trend information.

O Key words for data search on the core technology of the preliminary feasibility analysis

wearable AND device AND (part OR platform OR input OR output OR process OR power)

O Key words for data search on the upper level of core technology of the preliminary feasibility analysis

wearable AND device

In this paper the number of citation is calculated by taking into consideration the number of scrap or link by other sites of a trend information in a particular web site in order to assess the quality of the trend report like the number of citation of papers and patents, as well as the number. Therefore this paper assesses the stream of the market and technology accurately through the number of trend information and citation of the core technology of the preliminary feasibility analysis besides from papers and patents, and utilizes it as information to assume the market size and market share rate.

\section{Application on the Improvement Plan}

If the cases that utilize the spreading model like the CAGR method and Gomperz model is applied, the estimate differs greatly in the CAGR according to how the past data's standard was set. However, in the Gomperz model, a stable estimate can be deducted. From the graph below we can see that the G (application of the Gomperz model), when assuming the future estimation, shows the stabilization of the expansion of market size in the shape of S. Whereas the CAGR shows a big difference between the future estimate value calculated with the real results based on the CAGR of 2007 2014 
and the one done based on 2007 2010.

Even when utilizing the Gomperz model we need to be careful for the future estimate of market size differs according to the character of the standard data when applying the data of similar markets.

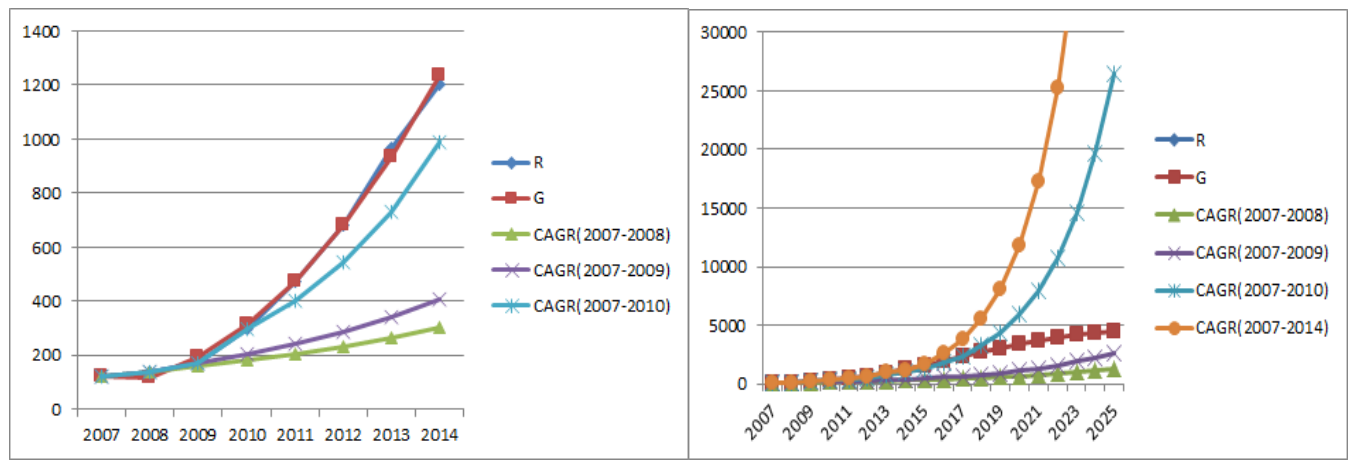

Figure 5. Comparison of CAGR and the Gomperz Model

In this paper, case study was done by utilizing real data and it was done on the basis that they were Catch-Up programs, and data was sufficient enough to analyze. First the direction of estimating market share rate is determined by utilizing patent index and by applying this the market share rate can be assumed. By understanding the relationship between patent index and the market share rate of similar markets, we can assume that all of the coefficient of the independent variable is (-). In this assumption the model needs to be designed in note of the fact that patent indexes affect the market share rate with a time difference. Though the fact that patent index has a (-) effect on the market share rate needs much understanding in the economical perspective, in cases in which the external variables like advertisement and marketing have a bigger influence that technical factors, there is a strong chance that a relationship as shown below exists.

$$
M S_{t}=a+b C P P_{t-1}+c P I_{t-1}+d T S_{t-1}+e P F S_{t-1}+\epsilon
$$

Therefore there is a possibility that the market share rate will become an over appropriate when the past market share rate data is assumed utilizing metric model without considering the coefficient from the patent index. This estimate is one in which the economic environment change or the marketing except for the expansion of market due to direct influence of the research and development program and so a revision of the market share rate estimate is needed. The market share rate estimate with the direction of prediction not applied shows that by 2020 approximately $60 \%$ will be achieved. However with the revision of the coefficient of patent index, $30 \%$ is predicted to be achieved. Thus in predicting the expansion of market share rate, a variety of influences exist besides the research and development program, causing the deduction of an estimate of over appropriate. Therefore the continuance of various researches will be needed.

The previous example is case of which market share rate was assumed utilizing the spreading model due to sufficient data of market share rates of similar markets. However there may be difficulty in gaining enough data to assume a spreading model even if a similar market is found in the research and development program. In this case previous researches relied on experts' surveys to predict the market share rate but in this study, we intend to utilize the metric model to do this. In this case, the past data of the specialized each similar market will substitute the dependent variable, and the independent variable will be divided into the adjustment independent variable which means the general influence that can be made on market share rates in similar markets, and the specific independent variable which is the influence that can directly affect market share rate of similar markets. 
Table 6. Adjustment Independent Variable

\begin{tabular}{|l|l|}
\hline \multicolumn{1}{|c|}{ Items } & Year \\
\hline \hline Progress of R\&D budget growth rate per year & $1993-2012$ \\
\hline Trade of technology, balance of technology trade(Export/import of technology) & $1991-2012$ \\
\hline Number of researchers per ten thousand people & $1992-2013$ \\
\hline percentage of basis/application/development in R\&D phase among R\&D costs & $1992-2013$ \\
\hline $\begin{array}{l}\text { percentage of government/enterprise/foreign part in each financial resource's } \\
\text { factors of research and development cost }\end{array}$ & $1999-2013$ \\
\hline
\end{tabular}

Table 7. Specific Independent Variable

\begin{tabular}{|l|l|}
\hline Items & Year \\
\hline similar markets' trade balance of the technology & $1993-2012$ \\
\hline $\begin{array}{l}\text { the percentage of the number of technical patents in similar markets(compared } \\
\text { to developed countries) }\end{array}$ & $1993-2013$ \\
\hline
\end{tabular}

Through the application of the Pooled OLS model, we can see that out of 17 independent variables, 13 are meaningful in the confidence interval. Among the adjustment independent variable, 'the percentage of development in the research and development phase among research and development costs' was assumed to affect the fluctuation of market share rate by $2.6 \%$ and 'the percentage of government in the each finances factors of research and development cost' by $2.2 \%$. Among the specific independent variable, 'the percentage of the number of technical patents in similar markets' was analyzed to affect the market share rate by $3.1 \%$, while 'the technical the trade balance of similar markets' was $1.7 \%$. Thus, with the equation assumed through the metric model, the market share rate is predicted through the assumption of the independent variable by applying the AR model per each independent variable, and its substitution in the estimation equation.

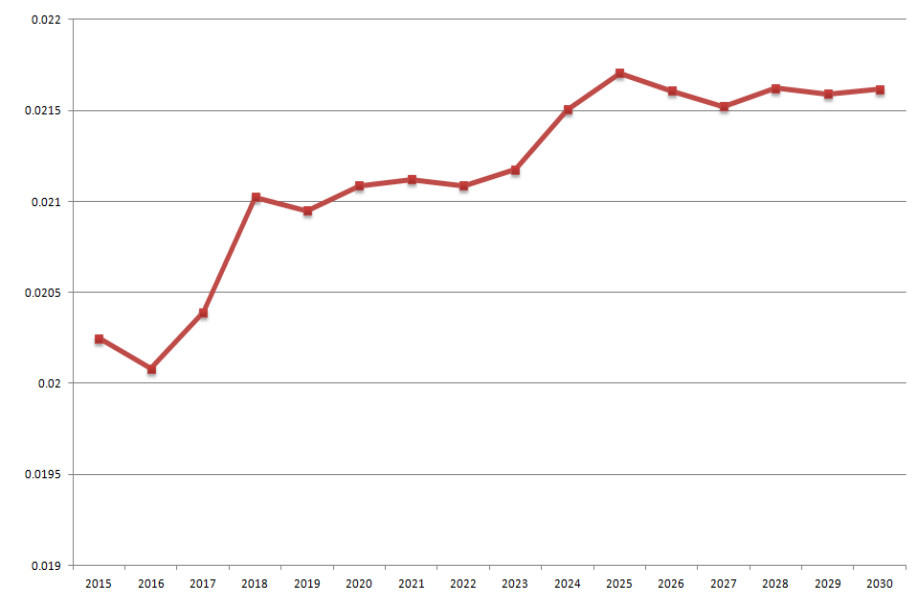

\section{Figure 6. Assumption of the Corresponding Technology's Market Share Rate}

The planning report, when compared to this result, assumed that the growth rate will increase the same rate every year, in the case of predicting market share rates through 2024 and 2030, but did not provide objective basis such as this. Therefore our results show that the market share rate will maintain the same consistent level starting from 2025 
by considering the independent variables that can influence market share rate, and so show a difference from the outcome of the planning report.

\section{Conclusions}

In this paper, the relative importance rank of benefit estimation hindrance factors was identified and the degree of repetition among these factors was deducted. The key challenges generating the benefit distinctions was identified by classifying the correlation between benefit distinctions and benefit estimation hindrance factors. According to the estimated importance rank, the improved benefit estimation guideline for market size and market share rate was provided and its application was analyzed.

\section{Acknowledgment}

This research was supported by the research program of KISTEP(Korea Institute of S\&T Evaluation and Planning).

\section{References}

[1] The OECD, "Assessing the social-economic impact of framework programme", OECD DSTI Report, (2007).

[2] T. L. Saaty, "How to make a decision: the analytic hierarchy process", European Journal of Operational Research, vol. 48, (1990), pp. 9-26.

[3] M. Sugeno, "Fuzzy measures and fuzzy integrals A survey", In Fuzzy Automata and Decision Processes, M. M. Gupta, G. N. Saridis and B. R. Gaines, eds., North-Holland, Amsterdam, (1977), pp. 89-102.

[4] J. H. Cho, B. Kim, C. H. Choi and H. Jeong, "A practical evaluation methodology on effective feasibility analysis of government R\&D program based on big data", Multimedia Tools and Applications, (2015).

[5] F. M. Bass, "A new product growth model for consumer durables", Management, Science, vol. 15, no. 5, (1969), pp. 215-277. 
International Journal of Database Theory and Application Vol.9, No.11 (2016) 